\title{
Experimental study of shale drillability with different bedding inclinations under varying wellbore pressure conditions
}

\author{
Shuai Chen ${ }^{1} \cdot$ Xiangchao Shi $^{1}$ (D) Heng Bao ${ }^{1,2} \cdot$ Leiyu Gao $^{1} \cdot$ Jie Wu$^{1}$
}

Received: 4 January 2021 / Accepted: 7 March 2021 / Published online: 24 March 2021

(c) The Author(s) 2021

\begin{abstract}
In the practice of shale gas development engineering, it is important to understand the physical and mechanical properties of shale. The bedding inclinations of shale are known to significantly influence its physical and mechanical properties. This study mainly examined the influence of bedding inclinations on drillability under different wellbore pressures. The bedding inclinations used in this study varied from $0^{\circ}$ to $90^{\circ}$, with a gradient of $15^{\circ}$. The wellbore pressure values used varied from 0 to $25 \mathrm{MPa}$, with a gradient of $5 \mathrm{MPa}$. The results show that the drillability index of shale increases exponentially with increasing wellbore pressure at different bedding inclinations. The proposed exponential empirical model can describe the relationship between the drillability index and wellbore pressure. When the wellbore pressure is less than $15 \mathrm{MPa}$, bedding inclinations significantly influence the drillability index, and the drillability index of shale shows a "W"-type variation trend as the bedding inclinations increase in the range of $0^{\circ}$ to $90^{\circ}$. The influence of bedding inclinations on drillability decreases gradually with increasing wellbore pressure. When the wellbore pressure increases to $25 \mathrm{MPa}$, the impact of bedding inclinations on drillability is virtually undetectable. The results of this study can provide reasonably insight into the effect of bedding inclinations on shale deformation under the drill bit, and useful prediction for the drillability index under in situ conditions.
\end{abstract}

Keywords Drillability $\cdot$ Wellbore Pressure $\cdot$ Bedding Inclinations $\cdot$ Shale

\section{Introduction}

Rock drillability was first proposed in 1927 by Tillson, who suggested that drillability reflects the degree of difficulty involved in breaking rock (White 1969). The concept has been used in formation classification, bit type selection, and drilling engineering design (Deng et al. 2007; Kelessidis 2011; O Yarali and Kahraman 2011). The physical and mechanical parameters and logging information of rock are often used to describe rock drillability (Liu et al. 2005; Morris and I. 1969; S Hoseinie et al. 2012; Spaar 1995; Zou and Chen 1996) but cannot completely reflect the nature of drillability. Microdrilling experiments are generally adopted as an effective method to evaluate rock drillability (HEAD

Xiangchao Shi

sxcdream@swpu.edu.cn

1 State Key Laboratory of Oil and Gas Reservoir Geology and Exploitation, Southwest Petroleum University, Chengdu, China

2 Research Center for Exploration and Development Technology, Yanchang Oilfield, Yanan, China
1951; Rollw 1962; Tarkoy and Hendron 1975). The simulated bottom-hole conditions of a microdrilling experiment can be used to objectively evaluate rock drillability under real drilling conditions. The results of field drilling show that bottom-hole pressure conditions significantly influence rock drillability (Carpenter and Chris 2015; Nas et al. 2010), and laboratory experiments have shown that there are significant differences in the same rock under different bottom-hole pressures (Mao et al. 2018). Strong dipping strata usually result in severe borehole inclination (Da et al. 2015), which is an important technical problem in drilling engineering. Many scholars have conducted a large amount of research on the anisotropy characteristics of shale(Kolawole et al. 2021). However, few studies have examined how bedding inclination causes borehole inclination (Teng et al. 2017), especially in simulated bottom-hole conditions. However, controlling the wellbore along a predetermined trajectory is critical for subsequent oil and gas production.

In this study, a microdrilling experiment was used to study shale drillability. The effect of varying bottom-hole pressure on shale drillability with different bedding inclinations was studied using the action of a polycrystalline

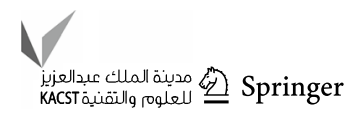


diamond composite (PDC) microdrill bit. This study is the first to consider the influence of bedding inclinations on drillability under different wellbore pressures. Previous scholars studied drillability from the perspective of experimental equipment and the drilling environment. The research in this paper not only includes the above factors but also includes the influence of rock properties on drillability. Finding out the influence of bedding inclinations on rock breaking of the drill bit can provide the scientific basis for the selection of PDC drill bit in different bedding inclinations formation. Studying the impact of shale on drillability can improve the efficiency of bit fracturing in the formation and thus reduce drilling cost.

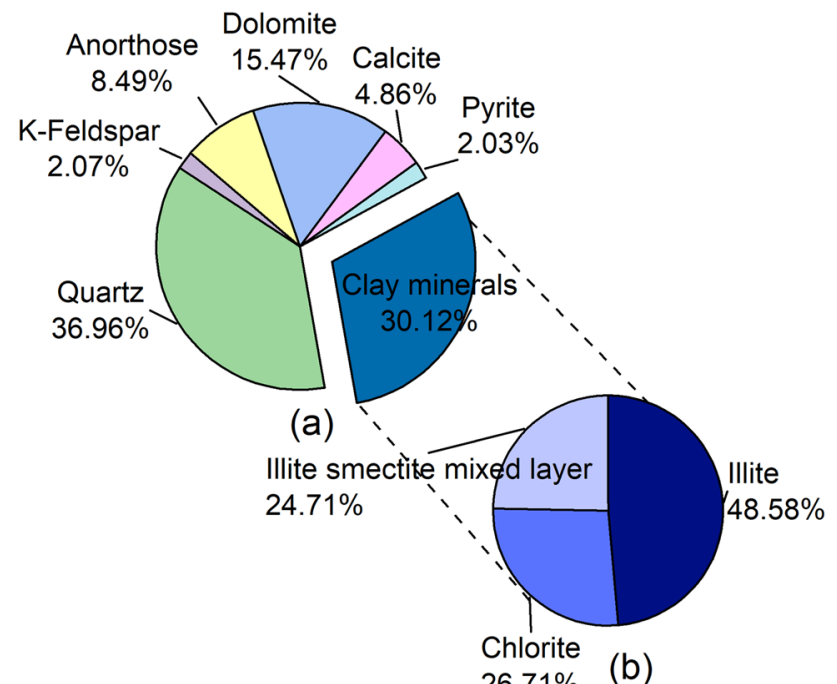

Fig. 1 XRD results for the shale used in this study: a total mineral contents; b clay mineral contents

\section{Materials and methods}

\section{Material characterization}

The shale samples considered in this study originated from Pengshui County, Chongqing, China (E108.51 N29.44). The mineral composition of shale is approximately $30 \%$ clay and $37 \%$ quartz. The mineral composition of the shale used in this study is shown in Fig. 1. The average porosity of the shale was measured as $3.27 \%$. The shale was too compact to measure the gas permeability. The bedding plane of the shale was well developed. The rock samples were prepared with different bedding inclinations. When the loading direction was parallel with the direction of the bedding plane, the inclination direction was set to $0^{\circ}$. When the loading direction was perpendicular to the bedding plane, the inclination direction was set to $90^{\circ}$ (see Fig. 2). The HS-YS2A rock acoustic testing instrument was used to measure the effect of

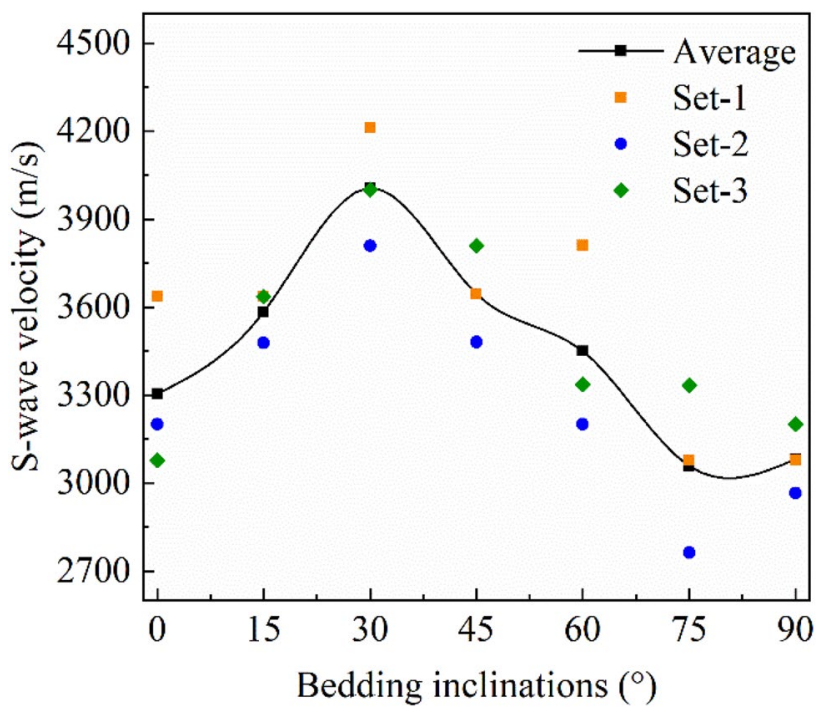

Fig. 3 Shear wave variation with bedding inclinations
Fig. 2 Preparation of rock samples with different bedding inclinations
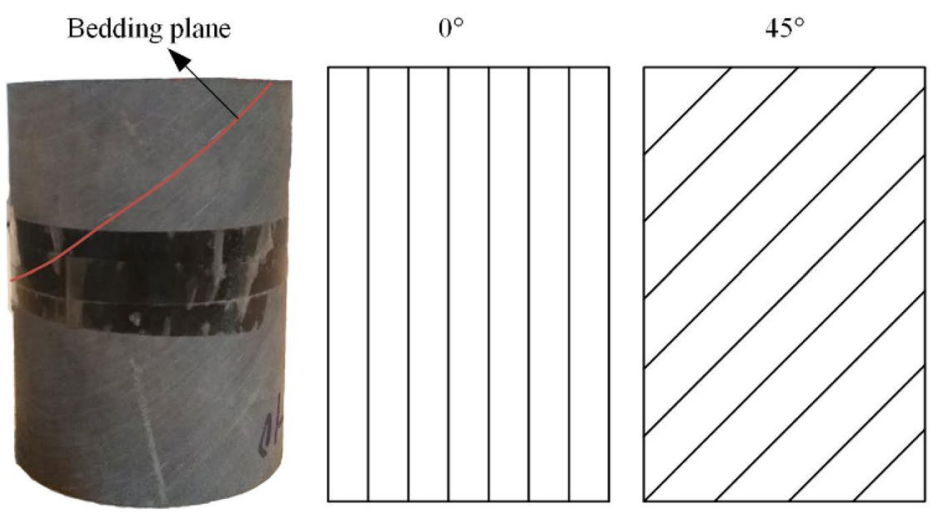

$90^{\circ}$

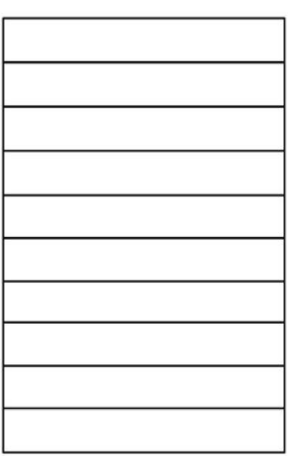


bedding planes on P-waves. The results are shown in Fig. 3. When the rock bedding inclination ranged from $15^{\circ}$ to $45^{\circ}$, the shear wave velocity of the rock tended to increase. When the rock bedding inclination ranged from $45^{\circ}$ to $75^{\circ}$, the shear wave velocity of the rock tended to decrease. The influence of bedding planes on acoustic waves was in good agreement with research on the anisotropy characteristics of shale (Tutuncu 2010; Tutuncu and AI Mese 2012). Therefore, the samples were well suited for studying the effect of bedding inclination on borehole inclination.

\section{Experimental method}

\section{Uniaxial compression test}

Uniaxial compression experiments were performed in a servo-hydraulic apparatus (GCTS RTR-2000, GCTS Company, Phoenix, AZ, USA). The specimens were processed into standard specimens with dimensions $25 \mathrm{~mm} \times 50 \mathrm{~mm}$. To limit the friction effect, the slenderness ratio of a compressive sample should be large enough. This can be manifested from a recommended slenderness ratio of 2 or larger for static compressive tests of rocks by the ISRM (Bieniawski and Bernede 1979). During the tests, the axial loading was carried out under the displacement control mode. The applied force and loading displacement were recorded simultaneously at the same sampling frequency during the entire deformation process. The maximum force applied along the axial direction of the sample was $600 \mathrm{kN}$. The displacement control at a strain rate of $0.2 \mathrm{~mm} / \mathrm{min}$ was used to obtain the stress-strain relationship of the rock samples.

\section{Drillability test}

The tests were carried out on an independently developed rock drillability apparatus (Mao et al. 2018). The detailed experimental apparatus, shown in Fig. 4, could simulate the bottom-hole conditions including confining pressure, wellbore pressure, pore pressure, bit weight, and rotational speed. The maximum value of the confining pressure, wellbore pressure, and pore pressure was $100 \mathrm{MPa}$. The rotation speed could be set freely between 0 and $200 \mathrm{rpm}$. The bit weight could be set freely between 0 and $3000 \mathrm{~N}$. The test samples were cylindrical specimens of $50 \mathrm{~mm}$ diameter and $80 \mathrm{~mm}$ height. Both the cone microdrill bit and PDC microdrill bit were used to test the rock drillability. The cone microdrill bit was assembled with eight blades and nine spacers and had a diameter of $31.75 \mathrm{~mm}$. The diameter of the PDC microdrill bit was $32 \mathrm{~mm}$ with two cutters. The two PDC cutters were installed at a back dip angle and roll angle of $20^{\circ}$ and $5^{\circ}$, respectively (see Fig. 5). In this study, the PDC rock drillability of shale for the PDC microdrill bit was tested, and the drilling parameters and evaluation methods were mainly based on the petroleum and natural gas industry standards of China (Standards 2016). The weight of the bit $(500 \mathrm{~N})$ and rotational speed $(55 \mathrm{rpm})$ for the PDC microdrill bit were set. When the confining pressure, wellbore pressure, and pore pressure reached the set values, the drilling began. The timer started when the drilling depth reached $0.2 \mathrm{~mm}$, the drill penetrated $3 \mathrm{~mm}$, the drilling time was recorded, and the drilling was stopped. The relationship (Standards 2016) between the rock drillability index $\left(K_{\mathrm{d}}\right)$ and drilling time (T) is defined in Eq. (1):

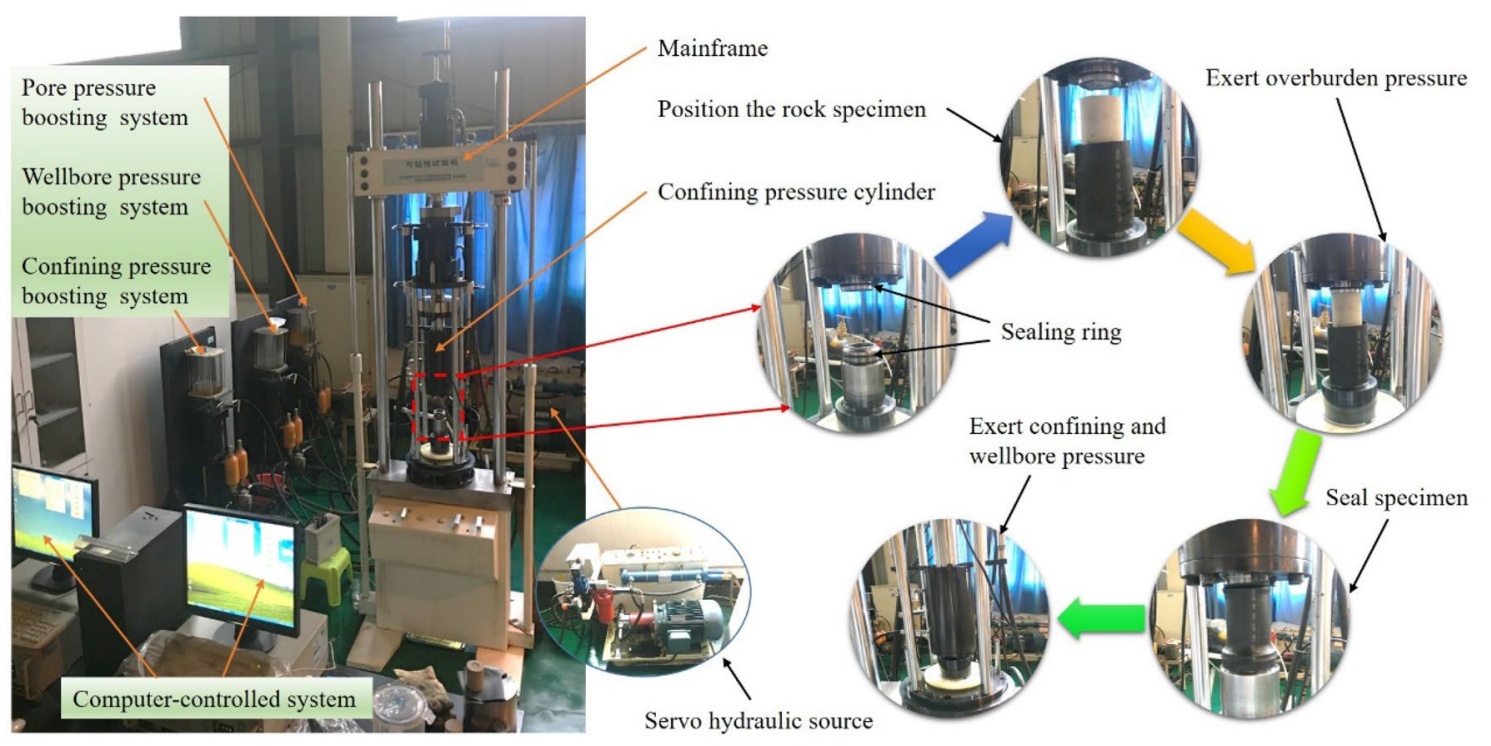

Fig. 4 Rock drillability test apparatus 
Fig. 5 PDC microdrill bit and cone microdrill bit

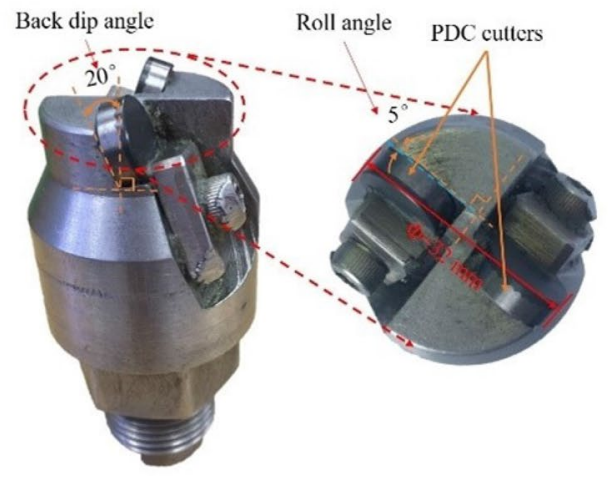

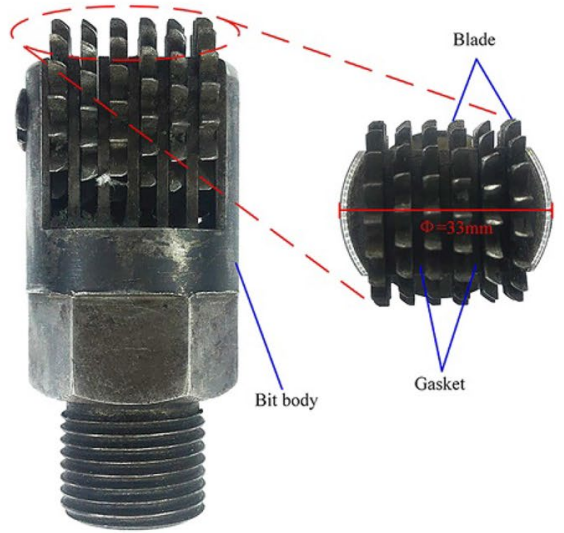

$K_{\mathrm{d}}=\log _{2} T$

\section{Results and discussion}

\section{Shale mechanical characteristics}

The stress-strain curves of shale from the uniaxial compression experiment are shown in Fig. 6a. The peak strength of the tested specimens was evaluated as shown in Fig. $6 \mathrm{~b}$. The peak strength displays "U"-type variation trends with respect to the bedding inclination. The minimum value of 66.91 $\mathrm{MPa}$ was obtained when the bedding inclinations were $45^{\circ}$. The maximum value was observed at $\beta=75^{\circ}$. The tested rock samples are shown in Fig. 7. Tensile splitting along the bedding plane occurred when the bedding inclination angle was $0^{\circ}$ and $15^{\circ}$. The bedding plane was nearly parallel to the loading direction, and tensile fractures were easily caused along the bedding planes. Shear along the bedding plane occurred when the rock bedding inclinations were $30^{\circ}$. However, when the rock bedding inclinations were $45^{\circ}$ and $60^{\circ}$, the shear along the bedding plane did not occur, and shear fractures through the bedding plane were extended. Shear through the bedding plane occurred on shale samples with bedding inclinations of $75^{\circ}$ and $90^{\circ}$. According to the experimental results, bedding inclinations have a significant impact on the failure behavior of shale. The experimental results of this paper are basically consistent with those of Yang et al.'s study (Yang et al. 2020).

\section{Influence of wellbore pressure on shale drillability with bedding inclinations}

Figure 8 depicts the ultimate shale sample after the test. Each sample was drilled into a pit, and no specific difference was observed. However, the time required to drill $3 \mathrm{~mm}$ was accurately recorded. According to Eq. (1), the drillability index could be obtained. The experimental results of
Fig. 6 Uniaxial compression experiment results of shale with different inclinations: a stressstrain curves, b peak strength

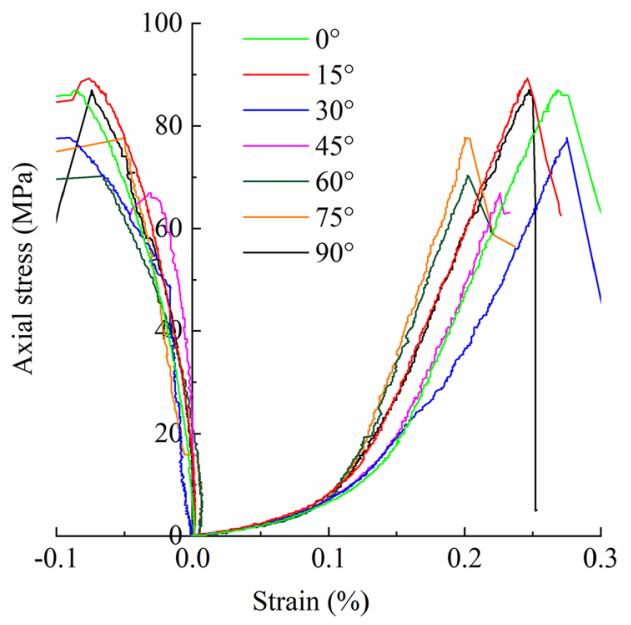

(a)

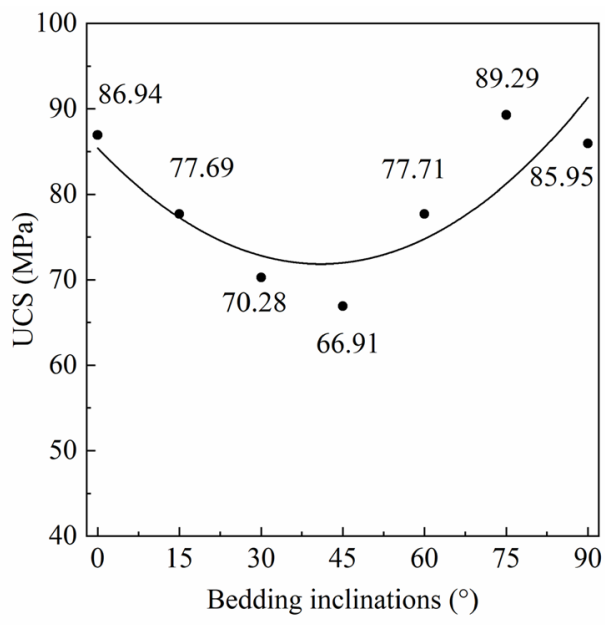

(b) 


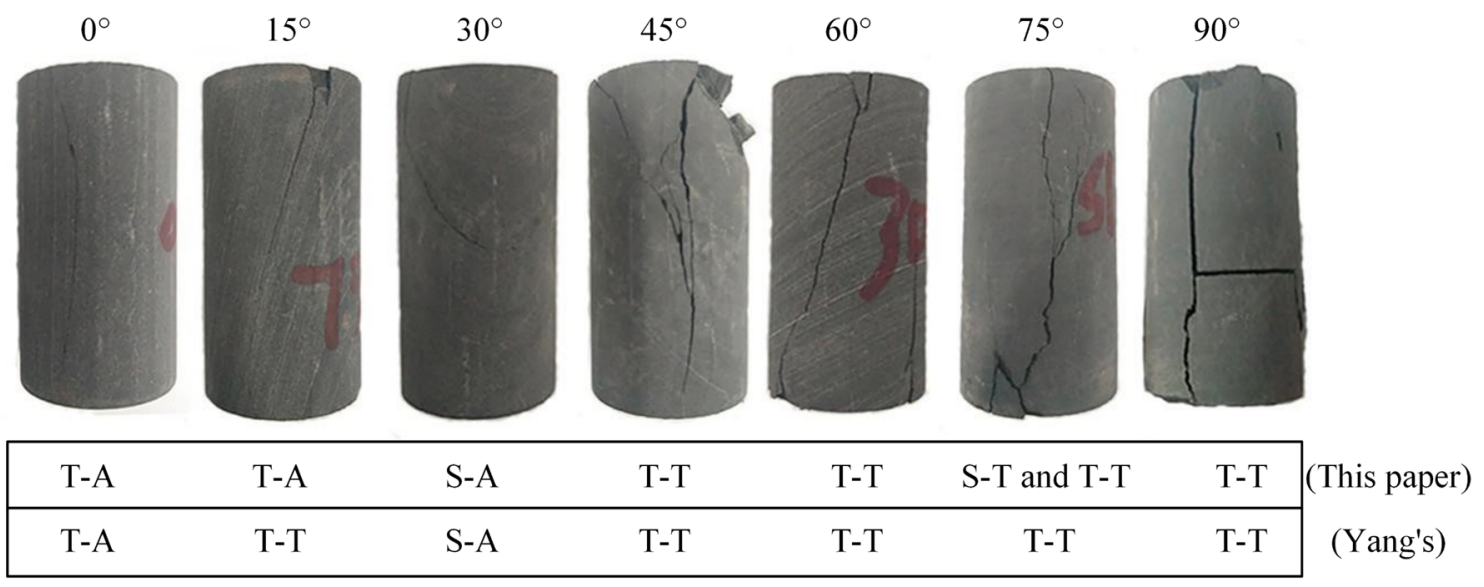

$\mathrm{T}-\mathrm{T}$ : Tensile splitting through bedding plane T-A: Tensile splitting along bedding plane

S-T: Shear through bedding plane

S-A: Shear along bedding plane

Fig. 7 Rock sample after uniaxial compression experiment

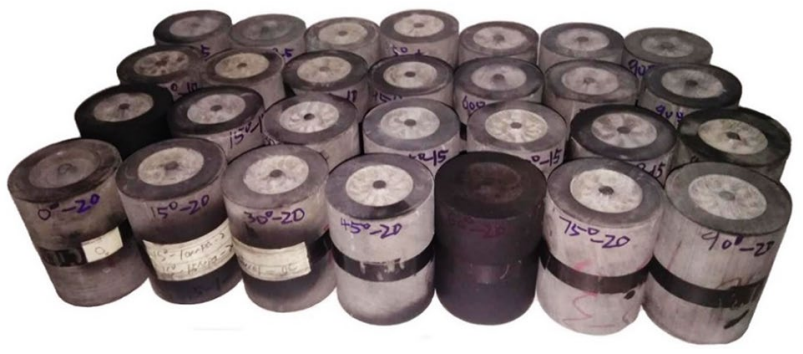

Fig. 8 Rock sample after drillability test

the drillability index of the shale samples under different bedding inclinations and wellbore pressures are shown in Table 1.

To understand the influence of wellbore pressures on the drillability of each bedding inclination sample, the relationship between wellbore pressure and drillability is plotted in Fig. 9. Figure 9 illustrates the impact of the bedding inclination on the drillability index under various wellbore pressures. It can be seen that the wellbore pressure has a significant effect on the drillability of shale with any bedding inclination and the drillability index increases with increasing wellbore pressure. The effect of wellbore pressure on the rate of penetration (ROP) is very significant in drilling engineering (Eckel 1958). As early as 1965, Maurer (Maurer 1965) experimentally demonstrated the effect of wellbore pressure on ROP. Maurer called this effect the holding down effect. According to his study, there are two reasons for the slow rate of mechanical drilling under wellbore pressure. First, the wellbore pressure significantly influenced the rock mechanics; second, drill cuttings cannot be removed from a borehole and brought to the surface, which can lead to repeated breakage of rock. To ensure the rapid removal of the drill cuttings, we used an inverted drill bit to break the rock in this study. According to Mao et al., the drillability index increases exponentially with increasing wellbore pressure for basalt, clay shale, and sandstone (Mao et al. 2018).

We found that the drillability index increases exponentially with increasing wellbore pressure for shales without different bedding surfaces. When the wellbore pressure is $<15 \mathrm{MPa}$, the drillability index increases almost linearly with increasing wellbore pressure. When the wellbore pressure is $\geq 15 \mathrm{MPa}$, the drillability index increases gently. This
Table 1 Drillability index of shale with different bedding inclinations

\begin{tabular}{lllllll}
\hline $\begin{array}{l}\text { Bedding inclinations } \\
\left({ }^{\circ}\right)\end{array}$ & \multicolumn{6}{l}{ Wellbore pressure $(\mathrm{MPa})$} \\
\cline { 2 - 6 } & 0 & 5 & 10 & 15 & 20 & 25 \\
\hline 0 & 6.97 & 7.29 & 8.55 & 8.24 & 8.04 & 8.05 \\
15 & 6.17 & 6.6 & 6.88 & 8.22 & 8.65 & 8.09 \\
30 & 5.81 & 6.68 & 7.33 & 8.5 & 8.55 & 8.19 \\
45 & 7.17 & 7.88 & 8.71 & 8.04 & 8.68 & 8.1 \\
60 & 5.97 & 6.93 & 7.24 & 7.88 & 8.39 & 8.16 \\
75 & 5.87 & 7.05 & 7.97 & 7.68 & 8.04 & 8.11 \\
90 & 5.58 & 7.53 & 7.62 & 7.78 & 8.00 & 8.07 \\
\hline
\end{tabular}


Fig. 9 Drillability index of shale under varying wellbore pressure
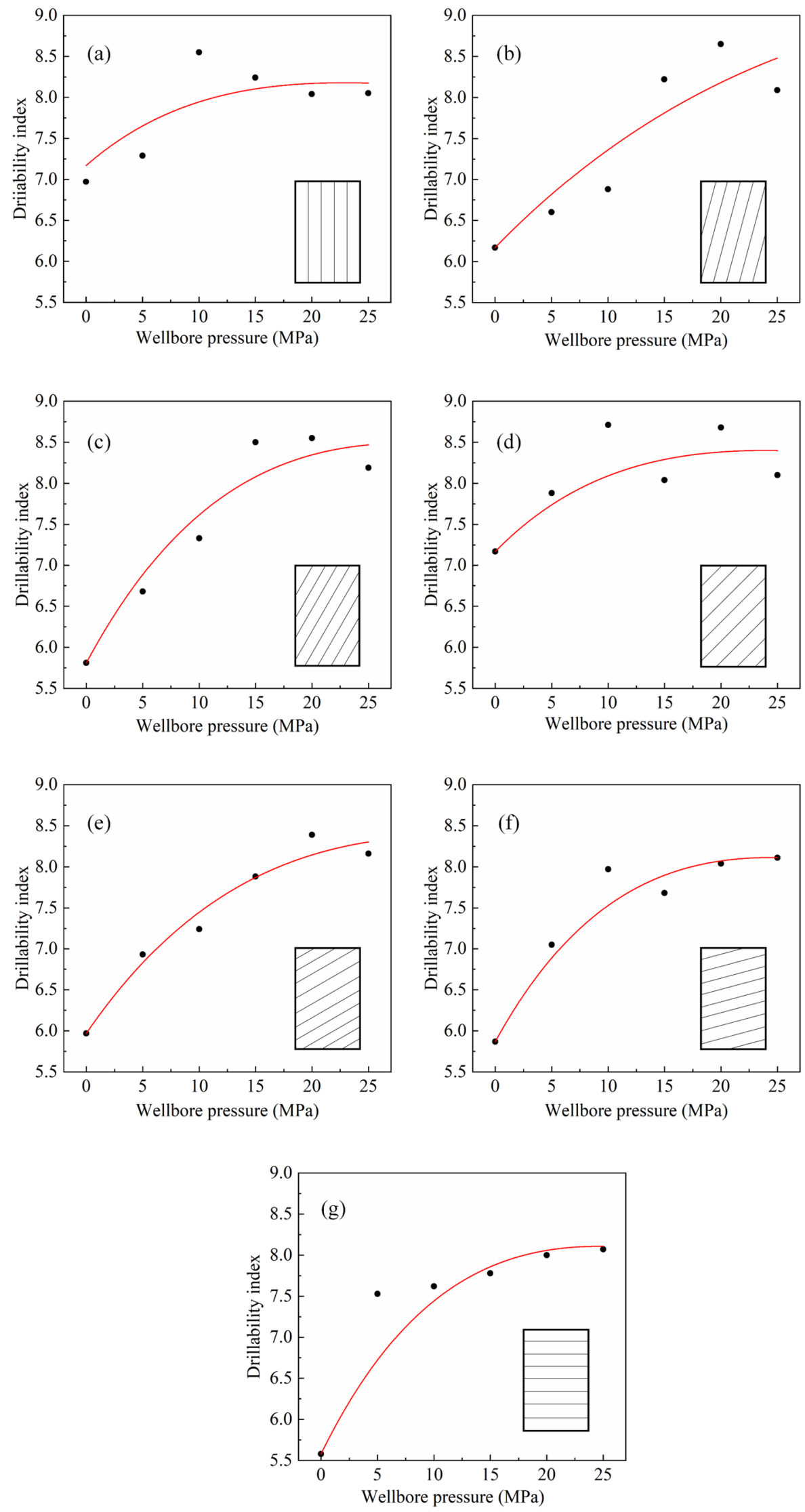
indicates that the exponential increase in the drillability index with increasing wellbore pressure is consistent with published studies; however, more experimental results are needed to confirm this finding. In this paper, the empirical equation for calculating the drillability index under different wellbore pressures is proposed as follows:

$K_{\mathrm{cd}}=K_{\mathrm{d}}+b \times P_{\mathrm{d}} \times e^{-a \times P_{\mathrm{d}}}$

where $K_{\mathrm{cd}}$ is drillability index related to wellbore pressure, $K_{\mathrm{d}}$ is drillability index at 0 wellbore pressure, $P_{\mathrm{d}}$ is wellbore pressures, and $a, b$ : Fitting coefficient.

Because the shale was very tight, pore pressure could not be applied, and the influence of pore pressure on shale could not be obtained. The effect of pore pressure on the drillability index was ignored in this study. Table 2 shows the fitting results of the experimental data using Eq. (2). It can be seen that the fitting effect was relatively good. The correlation coefficients were above 0.6 , most of which exceeded 0.9 . Therefore, the wellbore pressure influenced the drillability indexes with an exponential relation.

To further analyze the influence of wellbore pressure and bedding inclination on the drillability index, the relationship between wellbore pressure and drillability was plotted

Table 2 Fitting results of experimental data using Eq. (2)

\begin{tabular}{llll}
\hline $\begin{array}{l}\text { Bedding inclina- } \\
\text { tion }\left(^{\circ}\right)\end{array}$ & $a$ & $b$ & $R^{2}$ \\
\hline 0 & 0.04376 & 0.12000 & 0.67409 \\
15 & 0.01694 & 0.14108 & 0.84065 \\
30 & 0.03527 & 0.25674 & 0.93166 \\
45 & 0.04190 & 0.14000 & 0.60363 \\
60 & 0.03058 & 0.20044 & 0.96730 \\
75 & 0.04100 & 0.25000 & 0.92857 \\
90 & 0.04076 & 0.28000 & 0.83922 \\
\hline
\end{tabular}

again, as shown in Fig. 10. Figure 10a shows the relationship between the drillability index and wellbore pressure when the wellbore pressure is $<15 \mathrm{MPa}$ and $\geq 15 \mathrm{MPa}$, respectively. It can be clearly observed in Fig. 10a that when the wellbore pressure is $<15 \mathrm{MPa}$, the drillability index shows a "W" shape with a change in bedding inclinations. With increasing wellbore pressure, the influence of wellbore pressure on shale drillability decreases significantly. When the wellbore pressure is $25 \mathrm{MPa}$, there is a little difference in the drillability index for shales with different bedding inclinations.

The experimental results show that the bedding inclinations significantly influence drillability under low wellbore pressures $(<15 \mathrm{MPa})$, and high wellbore pressure reduces variability in drillability. The results of the cutting experiments by Wang et al. indicate that the torques during rock breakage show the same trend without considering the borehole conditions(Teng et al. 2017); however, the reasons for this are well worth investigating. It is well known that fractures tend to expand along weak planes, which may be an important reason for this phenomenon (Jiang et al. 2020; Song et al. 2020). Schormair and Thuro further proved by numerical simulation that this is still the case in the process of tool rock breakage (Schormair and Thuro 2007). The stress generated during the cutting tooth invasion must overcome the tensile or shear strength of the weak planes before the crack can be generated. The effects of the confining pressure and wellbore pressure are mainly reflected in the inhibition of crack propagation along the weak planes. With increasing confining pressure and wellbore pressure, the stress acting on the weak planes was sufficiently high to make the rock stiffer by increasing the difficulty for the induced crack to propagate along the weakest plane of the rock. As the wellbore pressure increases, the difference in the drillability index decreases. When the wellbore pressure is $25 \mathrm{MPa}$, the drillability of shale with different bedding inclinations is almost the same, as shown in Fig. 10. The
Fig. 10 Relations between drillability indexes and bedding inclinations under different wellbore pressures

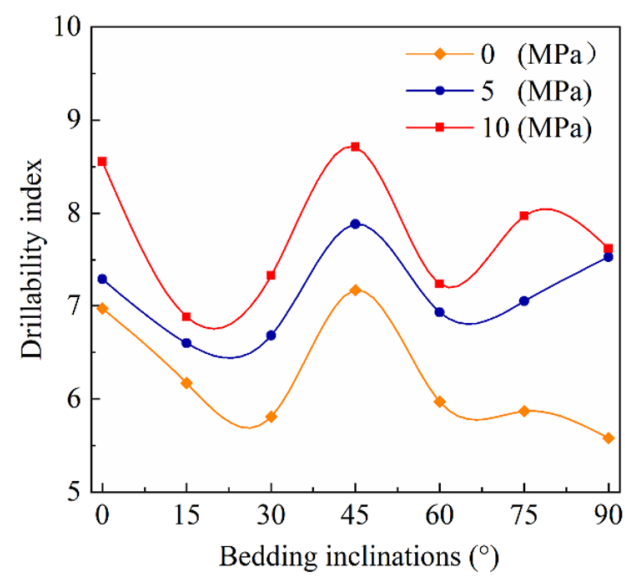

(a)

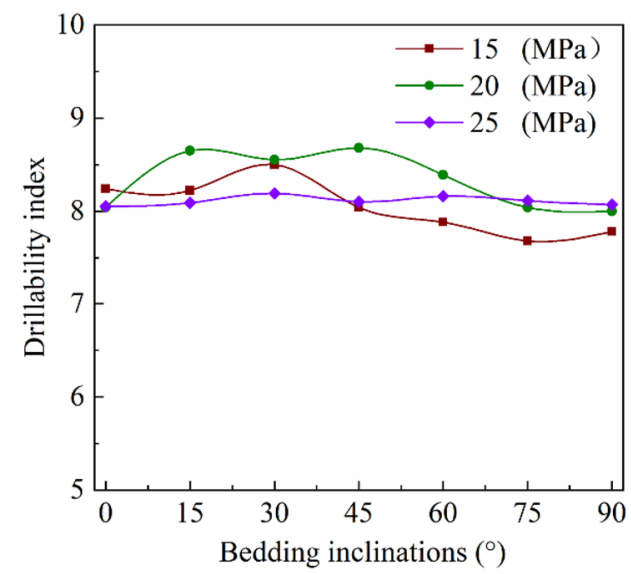

(b) 
mechanism of the influence of bedding inclinations on the invasion of bit teeth requires further research.

\section{Conclusion}

Drillability experiments were carried out for shale with different bedding inclinations under different wellbore pressures. The effect of borehole pressure and bedding inclinations on drillability was studied. Borehole pressure has a significant impact on the drillability index of shale. The drillability indexes of shale with different bedding inclinations increase exponentially with increasing borehole pressure. An empirical exponential model is proposed to describe the relationship between the borehole pressure and drillability index. This model can describe the effect of wellbore pressure on drillability. The bedding inclinations significantly influence the drillability index of shale, but the effect varies significantly under different borehole pressures. Under the condition of borehole pressure less than $15 \mathrm{MPa}$, the drillability indexes of shale show a "W" shape with increasing bedding inclinations. With increasing borehole pressure, the influence of bedding inclinations on drillability gradually decreases. When the wellbore pressure reaches $25 \mathrm{MPa}$, the bedding inclinations have little effect on the drillability indexes. In this study, the influence of temperature on the test results is not considered when the bit is simulated in the real rock-breaking environment of formation. The following research can consider the combined effect of temperature and wellbore pressure on rock drillability.

Funding This research was funded by National Natural Science Foundation of China, grant number 51774248 and U20A20266, and Sichuan International Science and technology innovation cooperation/Hong Kong, Macao, and Taiwan Science and technology innovation cooperation, grant number 2019YFH0166.

\section{Declarations}

Conflict of interest The authors declare no conflict of interest.

Open Access This article is licensed under a Creative Commons Attribution 4.0 International License, which permits use, sharing, adaptation, distribution and reproduction in any medium or format, as long as you give appropriate credit to the original author(s) and the source, provide a link to the Creative Commons licence, and indicate if changes were made. The images or other third party material in this article are included in the article's Creative Commons licence, unless indicated otherwise in a credit line to the material. If material is not included in the article's Creative Commons licence and your intended use is not permitted by statutory regulation or exceeds the permitted use, you will need to obtain permission directly from the copyright holder. To view a copy of this licence, visit http://creativecommons.org/licenses/by/4.0/.

\section{References}

Bieniawski ZT, Bernede MJ (1979) Suggested methods for determining the uniaxial compressive strength and deformability of rock materials. Int J Rock Mech Min SciGeomechAbstr 16:138-140. https://doi.org/10.1016/0148-9062(79)91451-7

Carpenter C (2015) Unique system for underbalanced drilling using air in the marcellus shale. J Petrol Technol 67:87-89. https://doi.org/ 10.2118/0215-0087-JPT

Da W, Wei Z, Xiao-xi Z (2015) Well-deviation control techniques for strong dipping strata. The China Continental Scientific Drilling Project, pp. 233-272

Deng L, Li Q, Gao Z (2007) New evaluation method of rock drillability. Drill Prod Technol 30:27-29

Eckel JR (1958) Effect of pressure on rock drillability. Trans Am Inst Min MetallEng 213:1-6. https://doi.org/10.2118/877-G

HEAD A L (1951) A drillability classification of geological formation. Paper presented at the 3rd World Petroleum Congress, The Hague, the Netherlands

Hoseinie S, Ataei M, Mikaiel R (2012) Comparison of some rock hardness scales applied in drillability studies. Arabian J SciEng 37:1451-1458. https://doi.org/10.1007/s13369-012-0247-9

Jiang Y, Yan P, Wang Y, Luan H, Chen Y (2020) Numerical investigations on shear behavior and failure mechanism of non-persistent jointed rocks. GeotechGeolEng 38:1639-1651. https://doi.org/10. 1007/s10706-019-01119-1

Kelessidis VC (2011) Rock drillability prediction from in situ determined unconfined compressive strength of rock. J South African Inst Min Metall 111:429-436

Kolawole O, Ispas I, Kumar M, Weber J, Zhao B, Zanoni G (2021) How can biogeomechanical alterations in shales impact caprock integrity and CO2 storage? Fuel 291:120149. https://doi.org/10. 1016/j.fuel.2021.120149

Liu X, Luo P, Meng Y, Yan J (2005) Evaluation on rock drill-ability by well logging data. Nat Gas Ind 25(69-71):10-11

Mao S, Shi X, Meng Y, Chen P, Zhuo X, Wong LNY (2018) Experimental investigation of rock drillability for three rock types under varying wellbore pressure conditions. Rock Mech Rock Eng 51:2439-2445. https://doi.org/10.1007/s00603-018-1472-7

Maurer W (1965) Bit-tooth penetration under simulated borehole conditions. J Petrol Technol 17:1-433. https://doi.org/10.2118/ 1260-pa

Morris IR (1969) Rock drillability related to a roller cone bit. Paper presented at the drilling and rock mechanics symposium, Austin, Texas

Nas SW, Gala DM, Cox P (2010) Deep air drilling application to enhance rate of penetration in extremely hard, abrasive and high temperature environment. Paper presented at the International oil and gas conference and exhibition in China, Beijing, China, 8-10 June

Rollw A (1962) Estimating drillability in the laboratory. Paper presented at the In: Proceedings, fifth symposium on rock mechanics, London, England

Schormair N, Thuro K (2007) Fracture pattern of anisotropic rock by drilling or cutting using the PFC. Paper presented at the 1st Canada-U.S. rock mechanics symposium, Vancouver, Canada

Song D, Chen Z, Ke Y, Nie W (2020) Seismic response analysis of a bedding rock slope based on time, frequency and time-frequency domains. EngGeol 274:105731. https://doi.org/10.1016/j.enggeo. 2020.105731

Spaar JR (1995) Formation compressive strength estimates for predicting drillability and PDC bit selection. Paper presented at the SPE/ IADC drilling conference, Amsterdam, Netherlands 
Standards C s O a G I (2016) Drilling engineering for the petroleum and natural gas-rock drillability measurement and its grading. SY/T 5426-2016,China (in Chinese)

Tarkoy P, Hendron A (1975) Rock hardness index properties and geotechnical parameters for predicting tunnel boring machine performance. Int J Rock Mech Min SciGeomechAbstr 14:211-212. https://doi.org/10.1016/0148-9062(77)90787-2

Teng W, Xiaohua X, Haiyan Z, Jingying Z, Yuheng L, Ming L (2017) Experimental study on longmaxi shale breaking mechanism with micro-pdc bit. Rock Mech Rock Eng 50:2795-2804. https://doi. org/10.1007/s00603-017-1255-6

Tutuncu AN (2010) Anisotropy, compaction and dispersion characteristics of reservoir and seal shales. Paper presented at the 44th US rock mechanics symposium and the 5th US/Canada Rock a, Salt Lake City, Utah

Tutuncu A, AI Mese (2012) Impact of fluids and formation anisotropy on acoustic, deformation and failure characteristics of reservoir shales and pure clay minerals. Harmonising Rock Engineering and the Environment, pp. 1341-1346 https://doi.org/10.1201/ b11646-253
White CG (1969) A rock drillability index. Rock Min 44:490. https:// doi.org/10.1080/00357529.1969.11764181

Yang SQ, Yin PF, Ranjith PG (2020) Experimental study on mechanical behavior and brittleness characteristics of longmaxi formation shale in Changning, Sichuan basin, China. Rock Mech Rock Eng 53:2461-2483. https://doi.org/10.1007/s00603-020-02057-8

Yarali O, Kahraman S (2011) The drillability assessment of rocks using the different brittleness values. Tunn Undergr Space Technol 26:406-414. https://doi.org/10.1016/j.tust.2010.11.013

Zou DY, Chen Y (1996) Study of determined the rock drillability with sonic interval transit time. Oil Drill Prod technol 18:27-30

Publisher's Note Springer Nature remains neutral with regard to jurisdictional claims in published maps and institutional affiliations. 